\title{
EDITORIAL
}

\section{Benefits and harms of early rehabilitation}

\author{
Brian H. Cuthbertson * and Shannon Goddard
}

๑) 2017 Springer-Verlag GmbH Germany and ESICM

The physical, psychological and cognitive morbidities occurring after critical illness are well identified, although they may have been overly attributed to the index critical illness and its treatment in the intensive care unit (ICU) [1-3]. How to prevent or treat these morbidities is less clear and there is still no clear signal for benefit from interventions commenced in, or after, the intensive care [4-7].

The strategy with the most promise is early rehabilitation (ER) commencing in the ICU or immediately after discharge. There is some supportive evidence that seems to suggest benefit for this regimen $[4,5]$, although the signal is far from consistent [7-11]. The biological rationale for benefit relates to the proposed impact of ER on the muscle dysfunction that occurs with prolonged bed rest (muscle atrophy) and during critical illness (muscle inflammation and necrosis) as well as the neuropathic changes also identified [12]. It seems credible that exercise could, at least partially, reverse the muscle atrophy seen in these patients, but whether it can reverse the more pathological changes related to inflammation and necrosis is less clear. Identifying the clinical or muscle phenotypes that may benefit from such early rehabilitation is still a major challenge and previous studies have tended to include heterogeneous groups of critically ill patients, not all of whom are likely to benefit [13].

This identified heterogeneity leads us to reflect on whether the concept of heterogeneity of treatment effect may well apply to this area of study [14]. That is to say that patients benefit from the treatment and some patients are harmed (or fail to benefit) with a net lack of treatment effect. Heterogeneity of treatment effect has most often been considered in mortality outcomes, but

*Correspondence: Brian.Cuthbertson@sunnybrook.ca Department of Critical Care Medicine, Sunnybrook Health Sciences Centre, Toronto, Canada the principle is equally useful here. If the baseline risk of an outcome (e.g. poor physical function) is very heterogeneous, which we know to be true in survivors of critical illness [15], and the relative effect of ER is constant, it stands to reason that some patients do not benefit (or may even be harmed). Randomized trials are, by definition, underpowered to identify subgroup effects and treatment heterogeneity is often missed by subgroup analyses, even with meta-analysis [14].

The recent AVERT study of ER in acute stroke raises concerns about the balance of benefits and harm related to ER strategies in acutely ill patients [16]. This study shows harm in the treatment group with regard to "favourable (neurological) outcome" (46\% vs 50\%; $p=0.004)$ and a possible trend for excess mortality ( $8 \%$ vs $7 \%, p=0.113$ ). The study was not able to fully explain the aetiology of this mortality signal but worsening neurological outcomes in the treatment group may contribute.

In the literature on ER in the ICU, a recent study demonstrated a benefit for ER in surgical ICU patients [5]. However, there was also a non-significant increase in hospital mortality in the treatment group ( $16 \%$ vs $8 \%, p=0.09$ ). This excess mortality may act as a competing risk for the study's primary and some secondary outcomes, potentially biasing these outcomes away from the null. Further, in a study by Kayambu et al., the 90-day mortality was higher in the treatment group (16\% vs $4 \%, p=0.08$ ) [17]; a study by Moss et al. showed a hospital mortality that was non-significantly higher in the treatment group (17\% vs $10 \%, p=0.25)$ [10], and a recent study of inspiratory muscle training by Bissett et al. showed an excess in-hospital mortality also in the treatment group ( $12 \%$ vs $0 \%, p=0.051)$ [18]. Importantly, other studies have not demonstrated such a signal and overall meta-analysis shows this signal to be nonsignificant. One explanation of this is that the observed

\section{Springer}


effect on mortality may be simply spurious. However, with absolute mortality differences of up to $12 \%$ [17], it is imperative to consider that this effect could be real. It is certainly possible that the baseline mortality risk is not uniform, resulting in a net result of "no effect" in individual studies and meta-analysis $[4,10,19]$. All existing analyses are underpowered for a mortality outcome, but unless we can accurately risk stratify patients and identify at-risk subgroups, this may be difficult to overcome.

As stated, there is a biological rationale for ER improving mobility outcomes, but there is also a plausible rationale by which ER could cause harm that relates to the potential for adverse cardiorespiratory events during critical illness whilst exercising. We know that myocardial events are related to outcome after critical illness [20] and that using dobutamine to drive oxygen delivery to supranormal levels in sepsis is associated with an excess mortality [21]. Of note, there is a moderate amount of accumulated safety data for ER, which has largely focused on events occurring during rehabilitation episodes [22]. These data are reassuring, but yet limited by low observation rates, possible publication bias and the very low level of detailed physiologic and electrocardiographic data on the impact of ER both during and after exercise sessions, which is essentially an exercise stress test [23-25].

We propose that there is a complex relationship between muscle-related outcomes and cardiorespiratory outcomes in our patients. In some patients muscle function and cardiorespiratory function may improve in a positively correlated manner during ER and this will likely lead to improved patient outcomes (Fig. 1, northeast quadrant). On other occasions the increased cardiorespiratory workload associated with ER may lead to harmful changes in myocardial oxygen supply/demand ratios or cause respiratory inadequacy causing low tissue oxygen delivery states leading to harm through adverse cardiac events (including death) (Fig. 1, south-west quadrant). Such cardiorespiratory limitations could occur even when muscle function is improving (Fig. 1, southeast quadrant). At very least such limitations may limit the patients' ability to exercise and an excess mortality may act as a competing risk for the ER outcomes.

It is similarly possible that ER may increase mortality in stroke patients through variations in blood pressure or oxygen delivery related to such cardiorespiratory events, leading to cerebral hypoperfusion states causing further stroke and other adverse neurological events which would worsen outcomes [16]. This result may be generalizable to patients with other severe neurological conditions in the ICU.

Despite the signal for excess mortality associated with ER not being statistically significant at this time, it must

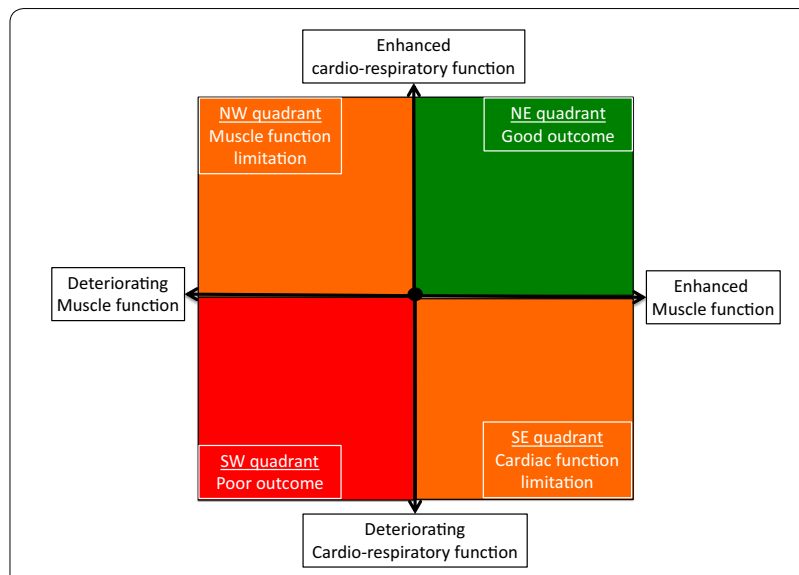

Fig. 1 The "myocardial" plane showing the proposed relationship between muscle function and cardiorespiratory function during early rehabilitation (ER). In studies of ER in ICU, net patient outcomes may depend on both muscle-related functional outcomes and cardiorespiratory outcomes (that may include cardiac death). It seems rational that these outcomes would move in the same direction, improved muscle function and improved cardiorespiratory function leading to a net outcome benefit i.e. the north-east quadrant of the myocardial plane. At times though, perhaps in the presence of higher levels of acute cardiac morbidity or co-morbidity, muscle-related outcomes may improve whilst cardiac outcomes worsen (south-east quadrant) with unpredictable effects on net patient outcome. Indeed both outcomes may worsen together (south-west quadrant) and lead to very poor net outcomes that could include death.

act as a warning to those undertaking studies in this field and for teams delivering these interventions in their daily practice; there is at least some biological rationale for harm from ER interventions. We strongly recommend that future studies identify mortality as a key outcome and have reasonable power to explore this outcome that is now key to the rigorous assessment of both the efficacy and the safety of these interventions. While this would require larger sample sizes, it is worth noting that a large trial of early rehabilitation in stroke patients recruited over 1000 patients per arm at multiple centres, demonstrating that large trials of complex rehabilitation interventions are feasible (although certainly expensive) [16]. Understanding the cause of death will also be important in elucidating attribution. Further, when patients with severe neurological conditions are being considered for inclusion into future studies, special consideration should be given to the justification for their inclusion, and there should be consideration to whether these patients warrant stratification at the time of group allocation and their outcomes treated as a key a priori subgroup analysis. 


\section{Compliance with ethical standards}

\section{Funding}

None.

\section{Conflicts of interest}

Neither author has competing interests for this article.

\section{Received: 9 March 2017 Accepted: 9 August 2017}

Published online: 24 August 2017

\section{References}

1. Cuthbertson BH, Roughton S, Jenkinson D, Maclennan G, Vale L (2010) Quality of life in the five years after intensive care: a cohort study. Crit Care 14:R6

2. Iwashyna TJ, Ely EW, Smith DM, Langa KM (2010) Long-term cognitive impairment and functional disability among survivors of severe sepsis. JAMA 304:1787-1794

3. Shankar-Hari M, Ambler M, Mahalingasivam V, Jones A, Rowan K, Rubenfeld GD (2016) Evidence for a causal link between sepsis and long-term mortality: a systematic review of epidemiologic studies. Crit Care BioMed Cent 20:101

4. Schweickert WD, Pohlman MC, Pohlman AS, Nigos C, Pawlik AJ, Esbrook CL et al (2009) Early physical and occupational therapy in mechanically ventilated, critically ill patients: a randomised controlled trial. Lancet 373:1874-1882

5. Schaller SJ, Anstey M, Blobner M, Edrich T, Grabitz SD, Gradwohl-Matis I et al (2016) Early, goal-directed mobilisation in the surgical intensive care unit: a randomised controlled trial. Lancet 388:1377-1388

6. Cuthbertson BH, Campbell MK, Stott SA, Vale L, Norrie J, Kinsella J et al (2010) A pragmatic multi-centre randomised controlled trial of fluid loading and level of dependency in high-risk surgical patients undergoing major elective surgery: trial protocol. Trials 11:41

7. Cuthbertson BH, Rattray J, Campbell MK, Gager M, Roughton S, Smith A et al (2009) The PRaCTICaL study of nurse led, intensive care follow-up programmes for improving long term outcomes from critical illness: a pragmatic randomised controlled trial. BMJ 339:b3723

8. Elliott D, McKinley S, Alison J, Aitken LM, King M, Leslie GD et al (2011) Health-related quality of life and physical recovery after a critical illness: a multi-centre randomised controlled trial of a home-based physical rehabilitation program. Crit Care 15:R142

9. Denehy L, Skinner EH, Edbrooke L, Haines K, Warrillow S, Hawthorne G et al (2013) Exercise rehabilitation for patients with critical illness: a randomized controlled trial with 12 months of follow-up. Crit Care 17:R156

10. Moss M, Nordon-Craft A, Malone D, Van Pelt D, Frankel SK, Warner ML et al (2016) A randomized trial of an intensive physical therapy program for acute respiratory failure patients. Am J Respir Crit Care Med 193:1101-10
11. Morris PE, Berry MJ, Files DC, Thompson JC, Hauser J, Flores L et al (2016) Standardized rehabilitation and hospital length of stay among patients with acute respiratory failure. JAMA 315:2694-2699

12. Hermans $G$, Van den Berghe $G$ (2015) Clinical review: intensive care unit acquired weakness. Crit Care 19.274

13. Cuthbertson BH, Wunsch H (2016) Long-term outcomes after critical illness. The best predictor of the future is the past. Am J Respir Crit Care Med 194:132-134

14. Iwashyna TJ, Burke JF, Sussman JB, Prescott HC, Hayward RA, Angus DC (2015) Implications of heterogeneity of treatment effect for reporting and analysis of randomized trials in critical care. Am J Respir Crit Care Med 192:1045-1051

15. Herridge MS, Chu LM, Matte A, Tomlinson G, Chan L, Thomas C et al (2016) The RECOVER Program: disability risk groups and 1-year outcome after 7 or more days of mechanical ventilation. Am J Respir Crit Care Med 194:831-844

16. AVERT Trial Collaboration group, Bernhardt J, Langhorne P, Lindley RI, Thrift AG, Ellery F et al (2015) Efficacy and safety of very early mobilisation within $24 \mathrm{~h}$ of stroke onset (AVERT): a randomised controlled trial. Lancet 386:46-55

17. Kayambu G, Boots R, Paratz J (2015) Early physical rehabilitation in intensive care patients with sepsis syndromes: a pilot randomised controlled trial. Intensive Care Med 41:865-74

18. Bissett BM, Leditschke IA, Neeman T, Boots R, Paratz J (2016) Inspiratory muscle training to enhance recovery from mechanical ventilation: a randomised trial. Thorax 71:812-819

19. Tipping CJ, Harrold M, Holland A, Romero L, Nisbet T, Hodgson CL (2017) The effects of active mobilisation and rehabilitation in ICU on mortality and function: a systematic review. Intensive Care Med 43:171-183

20. Croal BL, Hillis GS, Gibson PH, Fazal MT, El-Shafei H, Gibson G et al (2006) Relationship between postoperative cardiac troponin I levels and outcome of cardiac surgery. Circulation 114:1468-1475

21. Hayes MA, Timmins AC, Yau EH, Palazzo M, Hinds CJ, Watson D (1994) Elevation of systemic oxygen delivery in the treatment of critically ill patients. N Engl J Med 330:1717-1722

22. Nydahl P, Sricharoenchai T, Chandra S, Kundt FS, Huang M, Fischill M et al (2017) Safety of patient mobilization and rehabilitation in the intensive care unit. Systematic review with meta-analysis. Ann Am Thorac Soc 14:766-777

23. Weiss SA, Blumenthal RS, Sharrett AR, Redberg RF, Mora S (2010) Exercise blood pressure and future cardiovascular death in asymptomatic individuals. Circulation 121:2109-2116

24. Cole CR, Blackstone EH, Pashkow FJ, Snader CE, Lauer MS (1999) Heartrate recovery immediately after exercise as a predictor of mortality. $\mathrm{N}$ Engl J Med 341:1351-1357

25. Myers J, Prakash M, Froelicher V, Do D, Partington S, Atwood JE (2002) Exercise capacity and mortality among men referred for exercise testing. N Engl J Med 346:793-80 